Personality characteristics associated with susceptibility to false memories

\author{
Peter Frost \\ Sarah Sparrow \\ Jennifer Barry \\ Southern New Hampshire University
}

Citation: Frost, P., Sparrow, S. \& Barry, J. (2006). Personality Characteristics Associated with Susceptibility to False Memories. The American Journal of Psychology, 119(2), 193-204.

http://www.jstor.org/stable/20445334

Received for publication: August 20, 2004. Revision received: March 18, 2005. 


\begin{abstract}
This study examined whether certain personality characteristics are associated with susceptibility to false memories. Participants first answered questions from the Myers-Briggs Type Indicator in order to measure various personality characteristics.

They then watched a video excerpt, the simulated eyewitness event. They were next encouraged to lie about the videotaped event during an interview. A week later, some participants recognized confabulated events as being from the video. Two personality characteristics in particular - the introversion-extroversion and thinking-feeling dimensionswere associated with susceptibility to false memories.
\end{abstract}




\section{Personality characteristics associated with susceptibility to false memories}

Applied research has demonstrated that bias, as expressed by therapists (Loftus \& Ketcham, 1994) and forensic interrogators (Frost, Lacroix, \& Sanborn, 2003; Zaragoza, Payment, Ackil, Drivdahl, \& Beck, 2001), can lead interviewees to experience false memories, defined as false beliefs about the past that are experienced as memories (Heaps \& Nash, 2001). Interviewers might express their biases through feedback in order to shape witnesses' testimony, whether intentionally or unintentionally. Zaragoza et al. (2001) encouraged false memories by asking participants questions that would require them to confabulate an eyewitness account of an event. Participants first watched a videotaped excerpt then engaged in interviews during which they were asked to answer questions that required confabulation. For example, participants were asked, "Where was Delany bleeding?" when, in fact, he was not shown bleeding in the excerpt. The interviewer encouraged some confabulated responses with confirmatory feedback (e.g., "Yes, ___ is the correct answer") and provided neutral feedback for the remaining confabulated responses (e.g., "O.K. "). A week later, participants answered a recognition test that included questions about details they had confabulated during the interview. Participants recognized confabulated events as being from the videotaped event, even after they were warned that some questions during the prior interview referred to events that never happened. Furthermore, confirmatory feedback increased the frequency of false memories significantly more than neutral feedback. Zaragoza et al. concluded that social influence can be a potent catalyst to the creation of false memories.

However, it is unclear who might be susceptible to false memories encouraged by social influence. Perhaps there are individual differences associated with the false memory phenomenon. Few studies have addressed this issue.

Clancy, McNally, Schacter, Lenzenweger, and Pitman (2002) observed that false memories are associated with certain clinical and nonclinical dispositions. They examined false memories in participants who reported recovered memories of traumatic events that were unlikely to have occurred, namely abduction by space aliens. They used a variation of the DeeseRoediger-McDermott paradigm (Deese, 1959; Roediger \& Mc Dermott, 1995) to assess false recognition and recall. Participants studied lists of words. Each list was related to a nonpresented lure. For example, participants studied the following list of words associated with the non- 
presented word sweet: "sour, candy, sugar, bitter, good, taste ... cake, tart, pie." After hearing each list, participants were asked to recall as many words as they could remember. Participants then completed a new-old recognition test.

Clancy et al. (2002) found that people reporting memories of alien abduction were more likely than control participants to recall and recognize nonpresented words. In other words, participants who remembered incidents of alien abduction were more prone to false memories. In addition, Clancy et al. found that false recall and recognition were associated with measures of hypnotic suggestibility, depressive symptoms, and schizotypic features (such as magical ideation and absorption). ${ }^{1}$

Studies reveal that false memories are associated with a number of other psychological disorders. For example, false memories have been linked to dissociative symptoms (Clancy, Schacter, McNally, \& Pitman, 2000; Winograd, Peluso, \& Glover, 1998), symptoms of posttraumatic stress disorder (Bremner, Shobe, \& Kihlstrom, 2000), and symptoms of schizophrenia (Brebion et al., 2000).

False memories have also been associated with the ability to experience vivid visual imagery when recalling events. Hyman and his colleagues (Hyman \& Billings, 1998; Hyman \& Pentland, 1996) asked college students about various childhood events, including some events that, according to the students' parents, actually happened and some false events that the students' parents confirmed did not occur. For example, one of the false statements included the following: "When you were five you were at the wedding reception of some friends of the family and you were running around with some other kids, when you bumped into the table and spilled the punch bowl on the parents of the bride." Participants correctly remembered most of the true events but did not, at least initially, remember the false events. However, participants began recalling false events in subsequent interviews. Moreover, participants in Hyman's studies who recalled false memories of childhood events scored higher on scales that measure vividness of visual imagery than did people with more accurate memories.

${ }^{1}$ False recall rates were generally lower than false recognition rates for both control and experimental participants. The authors suggest that the recognition paradigm is a more sensitive assay for proneness to false memories than is the recall paradigm. 
Whereas most studies about individual differences linked to false memories have focused on clinical conditions or certain abilities, such as visual imagery, this study focuses on how common personality dispositions relate to the false memory phenomenon. The Myers-Briggs Type Indicator (MBTI) was used to measure personality. This test of personality was selected because it measures some personality dimensions that were hypothesized to be particularly relevant to susceptibility to false memories. The MBTI is a questionnaire that measures four personality dimensions based on Jungian typology: introversion-extroversion, sensationintuition, thinking-feeling, and judging-perceiving. Extroverts are described as focused on and energized by people and the world outside them, whereas introverts are focused on and energized by their inner world, of ideas, concepts, and feelings (Gailbreath, Wagner, Moffett, \& Hein, 1997). The sensation type of person pays attention to sensory details. Such people risk becoming so focused on the details of a situation that they tend to miss the big picture (Cloninger, 2000). In contrast, the intuitive person tends to make inferences and grasps the big picture. However, the intuitive type often does not know why he or she understands the big picture (Wippich, 1994). The thinking-feeling dimension refers to ways of making decisions. Feeling people make judgments based on their and others' emotions. They tend to make choices based on what will benefit the emotional well-being of themselves and others. Thinking people make decisions based on logic, principles, and reasons, even if the decisions are associated with negative affect (for themselves or others). The judging types include people who actively process, transform, and organize mental life, whereas perceiving people include those who receive information passively.

We examined false memories in this study by using the confabulation paradigm of Zaragoza et al. (2001). Susceptibility to false memories was correlated with the personality dimensions assessed by the MBTI. Hypotheses were made regarding three of the four personality dimensions. First, it was hypothesized that extroverts might be more susceptible to false memories, especially false information encouraged by confirmatory feedback. This is because extroverts tend to be more concerned with self-image than introverts (Hicks, 1985; Mill, 1984). This concern might motivate extroverts to accept and remember false information encouraged by confirmatory feedback during the interview process. The sensation-intuition dimension might also relate to susceptibility to false memories. Because sensation types rely on information they receive from their sensory experiences, they might be less susceptible to interviewer bias and the 
false memories it can encourage. Intuition types, in relying more on interpretations than on raw sensory data, might be more susceptible to false memories and confirmatory feedback. In an attempt to appease the feelings of others, feeling types might tend to accept and remember false information, especially that associated with confirmatory feedback. Thinking types might be less influenced by interviewer bias and the false memories they can encourage via confirmatory feedback because they are more concerned with logic than with pleasing others. In order to assess these hypotheses, scores on the personality dimensions measured by the MBTI were correlated with the frequency of false recognition.

\section{EXPERIMENT}

\section{METHOD}

\section{Participants}

The experiment included 40 undergraduate students from Southern New Hampshire University who were recruited on a voluntary basis. Participants received course credit for their participation. Each session included no more than two participants.

\section{Materials}

The MBTI. The MBTI (Form F) is a 166-item forced-choice questionnaire used to assess personality types based on Jung's analytic approach to personality. As described earlier, the MBTI assesses one set of opposing attitudes - introversion versus extroversion — and three sets of functions - sensation versus intuition, thinking versus feeling, and judging versus perceiving.

Research confirms that the MBTI is reliable and valid (Murray, 1990; Thompson \& Borrello, 1986). Internal consistency measurements with Cronbach's coefficient alpha have been found significant, with coefficients ranging from .76 to .86 for the introversion-extroversion scale, from .75 to .87 for the sensation-intuition scale, from .69 to .86 for the thinking-feeling scale, and from .80 to .84 for the judging-perceiving scale. The construct validity of the fourfactor model associated with the MBTI was examined using a confirmatory factor analysis (Plake \& Impara, 2001). The four-factor model appeared to be the best fit for the data compared with other competing models. As evidence of convergent validity, the MBTI continuous scores 
(used in this study) have been shown to be correlated with other comparable tests of personality, such as the California Psychological Inventory (Campbell \& Heller, 1987). Other studies have revealed that the four MBTI scales correspond to four of the big five personality domains, excluding emotional stability (Plake \& Impara, 2001). Although there is ample evidence that the personality types measured by the MBTI are valid, some of the types represented by the MBTI might be less elaborate than Jung originally envisioned. For example, extroversion, as measured by the MBTI, might be simply sociability rather than the more general "turning energy outward," as Jung suggested (Cloninger, 2000).

The video excerpt. Participants viewed a 15-min excerpt from the 1985 movie Clue (Paramount Pictures). The excerpt depicts a mystery in which a man is murdered at a dinner party held at a mansion. Many of the people gathered at the mansion had been blackmailed by the victim.

The yes-no recognition test. Recognition of false events was assessed by a yes-no test constructed in a format similar to previous research on forced confabulation (Ackil \& Zaragoza, 1998; Zaragoza et al., 2001). Twenty yes-no questions were asked in the following form: "When

you watched the video, did you see____ ? For example, "During the video, did you see the guests force open the locked door to the room with the screaming maid? YES OR NO" The test included four questions about false event items the participant confabulated during the previous interview described below (with 2 items followed by confirmatory feedback during the interview and 2 items followed by neutral feedback during the interview), 4 questions about false-event items the participant was not exposed to during the interview (to serve as a base rate), and 12 filler questions that included questions based on 5 true event questions from the interview, 4 additional true items from the video, and 3 new items. All false event items served as often as those asked about during the interview and those not referred to during the interview (base rate items). All types of questions were presented in random order.

\section{Procedures}

Participants gave informed consent during the first session. If they agreed to volunteer in the study, they were administered the MBTI. A code number was used to ensure anonymity and proper matching of results. Participants completed the MBTI at their own pace. 
Because personality characteristics can interact with aspects of the social environment, we took certain precautions with our interviewers and experimental design. For example, all variables were measured using a within-subjects design. For example, both types of feedback, both positive and neutral, provided during the interview were presented to each participant by the same interviewer. Therefore, any effects involving the interviewers should have been balanced across the levels of feedback. The types of information referred to during the interview, both true and false event details, were also presented within participants, with each interviewer asking about each type of information equally often. In addition, interviewers were trained to treat participants in a uniform manner, for example by reading instructions and following uniform test administration procedures. The procedures that followed the administration of the MBTI were similar to those Zaragoza et al. (2001) used. However, some exceptions are noted later. After completing the MBTI, participants viewed the 15-min excerpt from the movie Clue.

Immediately after viewing the videotaped excerpt, participants were separated and interviewed by different experimenters. Before the interview began, participants were told they must provide an answer to every question and were explicitly instructed to guess if they did not know an answer. During the interview, each participant responded to 12 questions about the movie excerpt after answering 2 questions about whether they had seen the movie Clue before and, if so, how long ago they had done so. Eight of the questions were true event questions about events from the videotaped excerpt. The four remaining questions were false event questions requiring the participant to confabulate answers to questions about events that never occurred in the video presentation. For example, in discussing a scene from the video, the experimenter asked, "How many guests did it take to force open the locked door to the room with the scream ing maid?" In order to answer this question, participants had to confabulate a response because although the guests did attempt to push the door open, it was only when the maid unlocked the door that the guests entered. If participants resisted answering the question, the experimenter prompted an answer by asking participants to provide their best guess.

Participants received feedback for their responses during the interview. Each participant received confirmatory feedback (e.g., "That's right, [four] is the correct answer") after confabulated responses to two of the false event questions. The two remaining confabulated responses were followed by neutral feedback delivered with flat affect (e.g., "[Four], OK"). To counterbalance, each of the false event questions served equally often in the confirmatory and 
neutral feedback conditions. All responses to true event questions were followed by neutral feedback. Session 1 ended with the completion of the interview. Participants were asked not to discuss the experiment with anyone.

During Session 2 (1 week later), participants completed the yes-no recognition test. Participants were warned that the experimenter in the first session made some mistakes and asked them questions about events that never really occurred in the video. Participants were told to answer yes-no questions based only on what they remembered from the video. These instructions were provided in order to avoid social pressure to respond consistently across test sessions. After participants completed the recognition test, they were debriefed about the true nature of the experiment.

\section{RESULTS}

First, it was important to determine whether participants had seen the movie Clue before the experiment. Most participants (85\%) indicated that they had not seen the movie Clue before seeing the excerpt during the experiment. The $15 \%$ of students who did report seeing the movie indicated that they saw the movie 5 years ago on average. Because the analyses for participants who had and had not previously seen the movie Clue led to the same results, these groups were combined for the following analyses. Data from the interview were analyzed to determine whether participants might have known they were being encouraged to confabulate during the interview. Participants overtly resisted answering false event questions $27 \%$ of the time, an indication that they felt forced to respond despite the instructions to provide an answer even if they had to guess. In contrast, participants overtly resisted answering true event questions $4 \%$ of the time.

Table 1 shows data from the recognition test, expressed as the proportion of "yes" responses as a function of question type. Consistent with previous research (Zaragoza et al., 2001), participants in the present study recognized false event items associated with confabulation. The proportion of "yes" responses to false event questions was greater than the base rate for false event questions (.16), for both neutral (.41) and confirmatory (.50) feedback conditions, $F(2,38)=7.42, p<.05$. Consistent with the confirmatory feedback hypothesis, recognition of false event items associated with confirmatory feedback did exceed that for neutral feedback, $t(39)=2.32, p<.05$. 
Table 1. Proportion of "yes" responses as a function of question type

\begin{tabular}{lc}
\hline Question type & Proportion of "yes" responses \\
\hline False event, confirmatory feedback & .50 \\
False event, neutral feedback & .41 \\
False event, base rate & .16 \\
True event & .66 \\
\hline
\end{tabular}

Descriptive statistics associated with the results of the MBTI are presented in Table 2. In order to assess the hypotheses, Spearman $r$ correlations were computed for the MBTI scores for each scale and the number of "yes" responses to false events associated with neutral and confirmatory feedback (Table 3).

Table 2. Descriptive statistics associated with the results of the Myers-Briggs Type Indicator as a function of personality dimension

\begin{tabular}{lrccc}
\hline & \multicolumn{4}{c}{ Score } \\
\cline { 2 - 5 } Personality dimension & Mean & Minimum & Maximum & \multicolumn{1}{c}{$S E$} \\
\hline Introversion-extroversion & 109.67 & 43.00 & 157.00 & 11.85 \\
Sensation-intuition & 129.80 & 88.00 & 156.00 & 7.74 \\
Thinking-feeling & 107.70 & 33.00 & 133.00 & 10.09 \\
Judging-perceiving & 92.90 & 42.00 & 139.00 & 12.49 \\
\hline
\end{tabular}

Note. The higher over 100 the score, the stronger the tendency toward introversion, intuition, feeling, or perceiving, depending on the subscale. Conversely, the lower below 100 the score, the stronger the tendency toward extroversion, sensation, thinking, or judging.

Regarding the first hypothesis, there was a moderate negative correlation between introversion-extroversion scores and recognition of false events previously associated with confirmatory feedback, $r=-.62, p<.05$. However, there was no significant relationship between the intro version-extroversion scores and recognition of false events previously associated with neutral feedback, $r=-.50$, although this relationship did approach significance, $p<.07$. Bear in mind that the higher the MBTI score for introversion-extroversion, the stronger the tendency toward introversion. The lower the MBTI score for introversion-extroversion, the higher the tendency toward extroversion. Therefore, the more extroverted participants were measured to be, the more likely they were to indicate they had seen false events when they were encouraged by confirmatory feedback. 
The second hypothesis was not confirmed. There was not a significant correlation $(p>$ $.05)$ between scores from the sensation-intuition scale and false recognition, regardless of the type of feedback used.

Regarding the third hypothesis, there was a significant correlation between scores from the thinking-feeling scale and the frequency of "yes" responses associated with false recognition of events previously linked with both neutral feedback, $r=.82, p<.05$, and confirmatory feedback, $r=.86, p<.05$. Note that the higher the MBTI score for thinking-feeling, the stronger

Table 3. Spearman $r$ correlations between Myers-Briggs Type Indicator (MBTI) scores and the number of "yes" responses to false events associated with neutral (false-neutral) and confirmatory (false-confirmatory) feedback and to true events associated with neutral $^{\text {a }}$ (true-neutral) feedback

\begin{tabular}{lccc}
\hline $\begin{array}{l}\text { Personality } \\
\text { dimension }\end{array}$ & $\begin{array}{c}\text { False- } \\
\text { Neutral }\end{array}$ & $\begin{array}{c}\text { False- } \\
\text { confirmatory }\end{array}$ & $\begin{array}{c}\text { True- } \\
\text { neutral }\end{array}$ \\
\hline Introversion-extroversion & -.50 & $-.62^{*}$ & .10 \\
Sensation-intuition & -.08 & -.09 & -.05 \\
Thinking-feeling & $.82^{* *}$ & $.86^{* *}$ & .18 \\
Judging-perceiving & -.11 & -.05 & -.09 \\
\hline
\end{tabular}

Note. Bear in mind that the higher the MBTI score the stronger the tendency toward introversion, intuition, feeling, or perceiving, depending on the sub scale. Conversely, the lower the MBTI score, the stronger the tendency toward extroversion, sensation, thinking, or judging.

${ }^{a}$ True event items were followed by neutral feedback only (therefore, there is no trueconfirmatory category).

${ }^{*} p<.05 . \quad{ }^{* *} p<.01$.

the tendency toward feeling. The lower the MBTI score for thinking-feeling, the stronger the tendency toward thinking. Therefore, the more feeling oriented participants were measured to be, the more likely they were to indicate they had seen false events.

\section{DISCUSSION}

The results of this experiment confirmed previous findings (Frost et al., 2003; Zaragoza et al., 2001) which demonstrated that questioning a witness about an event that encourages confabulation can later lead to his or her recognition of false information. Moreover, confirmatory feedback by an interviewer can increase the odds that a witness will falsely recognize confabulated events. 
Certain personality dimensions appear to be linked to false memories induced by confabulation during the eyewitness interview process. Confirmatory feedback is also associated with certain personality dimensions.

The findings of this study indicated that extroverted people appear to be slightly more susceptible to false recognition of events associated with confirmatory feedback than are introverted people. Perhaps this is because extroverts tend to be more attentive to social cues. As noted earlier, they also tend to be more concerned with their self-image (Cloninger, 2000). Therefore, they might find confirmatory feedback more salient and re warding than introverts. Given the lack of difference between confirmatory and neutral feedback overall, however, the difference between the introverted and extroverted tendencies was small at best.

Of the MBTI scales, the thinking-feeling dimension was shown to have the strongest relationship with false memories. Because feeling type people tend to be more concerned with the feelings of others and group harmony, it was initially hypothesized that they would be more likely than thinking type people to accept and remember false events associated with confirmatory feedback by the interviewer. Although this hypothesis was confirmed by the findings, the feeling types were also strongly associated with recognition of false events followed by neutral feedback. Explicit social feedback is not necessary in order to influence false recognition in feeling type people. Perhaps they are concerned with pleasing or are influenced by the interviewer at a more implicit level.

What is unclear is why people who base decisions more on emotions than on logic tend to be susceptible to reporting recognition of false memories. For example, the feeling dimension has an internal and external component: making decisions based on one's own emotions and making decisions based on others' emotions. Which aspect of the feeling type is associated with susceptibility to false memories? Perhaps feeling type participants were more likely to report recognizing false events because the confirmatory feedback was more reinforcing for them than for the thinking type participants. Or the feeling type participants were more interested in pleasing the interviewer. This seems less likely because they were informed that the interviewer referred to false information before the recognition test in order to avoid demand characteristics (although they might have forgotten which details were linked to the misinformation at the time of testing). Future research should focus on why there is a strong relationship between the thinking-feeling dimension and false memories. 
Although this study found that certain individual differences correlate with false recognition, some studies conflict on this matter. For example, some studies have found a relationship between dissociative experiences and false memory (Eisen, Morgan, \& Mickes, 2002; Porter, Birt, Yuille, \& Lehman, 2000). Other studies have found no relationship between dissociative experiences and false memory (Mazzoni, Loftus, Sietz, \& Lynn, 1999; Wilkinson \& Hyman, 1998). In their review of this literature, Lynn, Knox, Fassler, Lilienfeld, and Loftus (2004) suggested that, in aggregate, these studies indicate that people with dissociative tendencies have at least a marginal risk of developing false memories. It remains to be seen whether nonclinical personality characteristics, such as extroversion and feeling types, will lead to similar inconsistencies in relation to false recognition.

One of the reviewers of this article suggested that the scales on the MBTI should be correlated with true memories because the association of such personality types as extroversion and feeling with false recognition could reflect a response bias. The finding that there were no correlations between the personality types measured by the MBTI and true event items suggests that response bias did not account for the results in this study. However, because true event items in this study were associated only with neutral feedback, future research should investigate this possibility with true event items and confirmatory feedback. This is especially relevant re garding the finding that extroversion was associated with false recognition only when confirmatory feedback was used. Would the same relationship hold if extroversion were compared with true recognition and confirmatory feedback? If so, then response bias probably would account for the results, a finding that would still be enlightening regarding the topic of personality and false recognition.

Although this study links false memories with certain personality characteristics, the nature of correlational studies does not permit a causal inference. However, this study does indicate that certain personality pro files might predict different levels of susceptibility to false memories. By further understanding how personality can induce or inoculate us from false memories, we might one day be able to fully understand the mechanisms behind the false memory phenomenon.

\section{Notes}


This study was funded by a summer research grant provided by Southern New Hampshire University. We would like to thank two lab assistants, Angelet Dupras and Sarah Mitchell, for their help running the experiments. Correspondence about this article should be addressed to Peter Frost, Department of Psychology, Southern New Hampshire University, 2500 North River Road, Manchester, NH 03106-1045 (e-mail: p.frost@snhu.edu). Received for publication August 20, 2004; revision received March 18, 2005.

\section{References}

Ackil, J. K., \& Zaragoza, M. S. (1998). Memorial consequences of forced confabulation: Age differences in susceptibility to false memories. Developmental Psychology, 34, 13581372.

Brebion, G., Amador, X., David, A., Malaspina, D., Sharif, Z., \& Gorman, J. M. (2000). Positive symptomatology and source-monitoring failure in schizophrenia: An analysis of symptom-specific effects. Psychiatry Research, 95, 119-131.

Bremner, J. D., Shobe, K. K., \& Kihlstrom, J. S. (2000). False memories in women with selfreported childhood sexual abuse: An empirical study. Psychological Science, 11, 333337.

Campbell, J. B., \& Heller, J. F. (1987). Correlations of extraversion, impulsivity and sociability with sensation seeking and MBTI introversion. Personality and Individual Differences, 8 , 133-136.

Clancy, S. A., McNally, R. J., Schacter, D. L., Lenzenweger, M. F., \& Pitman, R. K. (2002). Memory distortion in people reporting abduction by aliens. Journal of Abnormal Psychology, 111(3), 455-461.

Clancy, S. A., Schacter, D. L., McNally, R.J., \& Pitman, R. K. (2000). False recognition in women reporting recovered memories of sexual abuse. Psychological Science, 11, 26-31.

Cloninger, S. C. (2000). Theories of personality: Understanding persons. Upper Saddle River, NJ: Prentice Hall. Deese, J. (1959). On the prediction of occurrence of particular verbal intrusions in immediate recall. Journal of Experimental Psychology, 58, 17-22.

Eisen, M. L., Morgan, D. Y, \& Mickes, L. (2002). Individual differences in eyewitness memory and suggestibility: Examining the relations between acquiescence, dissociation, and 
resistance to misleading information. Personality and Individual Differences, 33, 553571.

Frost, P. J., Lacroix, D., \& Sanborn, N. (2003). Enhancing false recognition rates with confirmatory feedback: A phenomenological analysis. American Journal of Psychology, 116, 515-525.

Gailbreath, R. D., Wagner, S. L., Moffett, R. G., \& Hein, M. B. (1997). Homogeneity in behavioral preferences among U.S. Army leaders. Group Dynamics: Theory, Research, and Practice, 7(3), 222-230.

Heaps, C. M., \& Nash, M. (2001). Comparing recollective experience in true and false autobiographical memories. Journal of Experimental Psychology: Learning, Memory, and Cognition, 27(4), 920-930.

Hicks, L. E. (1985). Is there a disposition to avoid the fundamental attribution error? Journal of Research in Personality, 19, 436-456.

Hyman, I. E., \& Billings, F. J. (1998). Individual differences and the creation of false childhood memories. Memory, 6, 1-20.

Hyman, I. E., \& Pentland J. (1996). The role of mental imagery in the creation of false childhood memories. Journal of Memory and Language, 35, 101-117.

Loftus, E. F., \& Ketcham, K. (1994). The myth of repressed memory: False memories and allegations of sexual abuse. New York: St. Martin's.

Lynn, S. J., Knox, J. A., Fassler, O., Lilienfeld, S. O., \& Loftus, E. F. (2004). Memory, trauma, and dissociation. In G. Rosen (Ed.), Posttraumatic stress disorder: Issues and controversies (pp. 163-186). Chichester, England: Wiley.

Mazzoni, G. A. L., Loftus, E. R, Seitz, A., \& Lynn, S. J. (1999). Changing beliefs and memories through dream interpretation. Applied Cognitive Psychology, 13, 125-144.

Mill, J. (1984). High and low self-monitoring individuals: Their decoding skills and empathie expression. Journal of Personality, 52, 372-388.

Murray, J. B. (1990). Review of research on the Myers-Briggs Type Indicator. Perceptual and Motor Skills, 70, 1187-1202.

Plake, B. S., \& Impara, J. C. (2001). The fourteenth mental measurements yearbook. Lincoln, NE: Buros Institute of Mental Measurements. 
Porter, S., Birt, A. R., Yuille, J. C, \& Lehman, D. R. (2000). Negotiating false memories: Interviewer and rememberer characteristics relate to memory distortion. Psychological Science, 11, 507-510.

Roediger, H. L. Ill, \& McDermott, K B. (1995). Creating false memories: Remembering words not presented in lists. Journal of Experimental Psychology: Learning, Memory, and Cognition, 21, 803-814.

Thompson, B., \& Borrello, G. M. (1986). Construct validity of the Myers-Briggs Type Indicator. Educational and Psychological Measurement, 46, 745-752.

Wilkinson, C, \& Hyman, I. E. (1998). Individual differences related to two types of memory errors: Word lists may not generalize to autobiographical memory. Applied Cognitive Psychology, 12, S29-S46.

Winograd, E., Peluso, J. P., \& Glover, T A. (1998). Individual differences in susceptibility to memory illusions. Applied Cognitive Psychology, 12, S5-S27.

Wippich, W. (1994). Intuition in the context of implicit memory. Psychological Research, 56, 104-109.

Zaragoza, M. S., Payment, K. E., Ackil, J. K., Drivdahl, S. B., \& Beck, M. (2001). Interviewing witnesses: Forced confabulation and confirmatory feedback increase false memories. Psychological Science, 12(6), 473-477. 